Document downloaded from:

http://hdl.handle.net/10251/108648

This paper must be cited as:

Marzal-Romeu, S.; Salas-Puente, RA.; González Medina, R.; Garcerá, G.; Figueres Amorós, E. (2018). Current challenges and future trends in the field of communication architectures for microgrids. Renewable and Sustainable Energy Reviews. 82(2):3610-3622. doi:10.1016/j.rser.2017.10.101

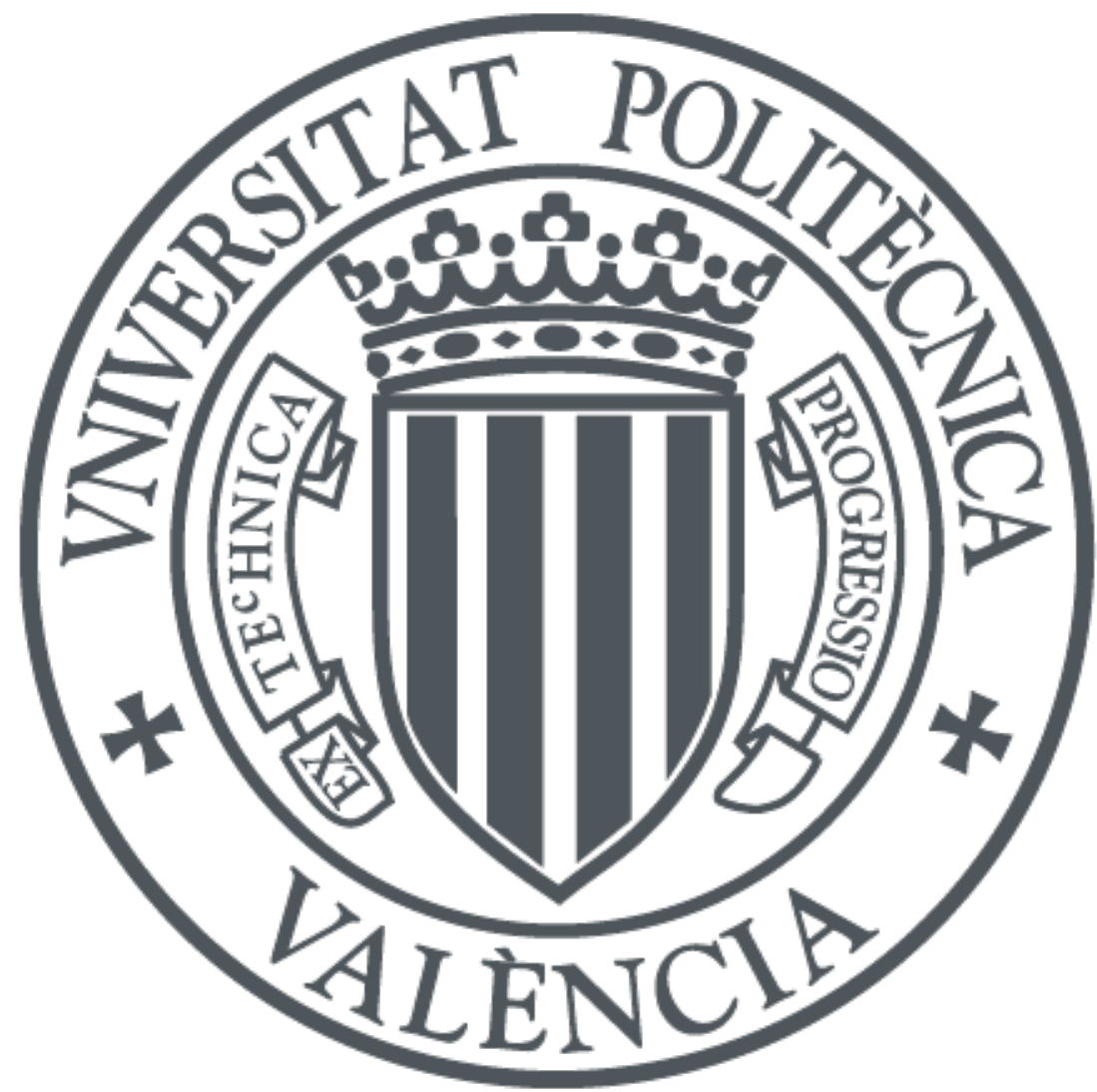

The final publication is available at

https://doi.org/10.1016/j.rser.2017.10.101

Copyright Elsevier

Additional Information 


\title{
CURRENT CHALLENGES AND FUTURE TRENDS IN THE FIELD OF COMMUNICATION ARCHITECTURES FOR MICROGRIDS
}

\begin{abstract}
The concept of microgrid has emerged as a feasible answer to cope with the increasing number of distributed renewable energy sources which are being introduced into the electrical grid. The microgrid communication network should guarantee a complete and bidirectional connectivity among the microgrid resources, a high reliability and a feasible interoperability. This is in a contrast to the current electrical grid structure which is characterized by the lack of connectivity, being a centralized-unidirectional system. In this paper a review of the microgrids information and communication technologies (ICT) is shown. In addition, a guideline for the transition from the current communication systems to the future generation of microgrid communications is provided. This paper contains a systematic review of the most suitable communication network topologies, technologies and protocols for smart microgrids. It is concluded that a new generation of peer-to-peer communication systems is required towards a dynamic smart microgrid. Potential future research about communications of the next microgrid generation is also identified.
\end{abstract}

\section{INTRODUCTION}

The basic structure of the electrical grid has almost remained unchanged up to now. For decades the grid has delivered energy from remote power plants towards consumer loads in a unidirectional and centralized manner [1]. Currently, the generation, distribution and consumption of electricity is evolving at an impressive speed, driven by both the high penetration of distributed energy resources (DERs) that are being incorporated to the grid and the advances in information and communication (ICT) technologies. In this context the microgrid concept has emerged. A microgrid forms an autonomous power system that needs a ubiquitous information layer for coordination, monitoring and control of all the distributed energy resources deployed in it. Nowadays, most microgrids still rely on legacy communication networks. However, microgrid energy systems are transitioning from centralized systems towards distributed energy systems with more demanding reliability, security, and performance requirements. Therefore, a flexible and adaptive communication network architecture is required. To make effective decisions, power designers will need a basic understanding of communication network technologies that should be implemented on microgrids. Consequently, a description of the past, current and future trends as well as the fundamentals about communications for deploying intelligent microgrids is included in this paper. The basics of today's communications in microgrids are also described. Next, the main challenges in the communication requirements of intelligent microgrids are defined, leading to the proposal of a new generation of smart microgrids. The most suitable communication architecture (network topologies, communication protocols and technologies) for the deployment of this proposal is discussed. Next, a new generation of peer-to-peer (P2P) communication systems for the future microgrids is proposed. Finally, new research topics for the transition to future microgrids are shown. 


\section{TODAY'S MICROGRID STATUS}

A Microgrid (MG) (Figure 1) is a low voltage distributed network of individual consumers within a building, campus, or community that are interconnected with, at least, one shared distributed generation source (DG). A microgrid consists of a variety of loads, microsources (MS) and energy storages systems (SS), called distributed energy resources (DERs), that acts as a single controllable entity with respect to the main grid [2], [3], [4]. Microgrid operates mostly connected to the main distribution network but they can be automatically disconnected from the main grid at the point of common coupling (PCC) in case of faults to provide a minimum level of service during a utility grid power outage. They can be reconnected once the fault has disappeared [5], [6]. Microgrids must have their own control to ensure the correct operation and coordination of the different DERs. A Microgrid Controller (MGC) is usually needed to manage the operation within the microgrid, the energy flows and the interconnection with the main grid. In addition, all microgrid devices need to communicate with the MGC.

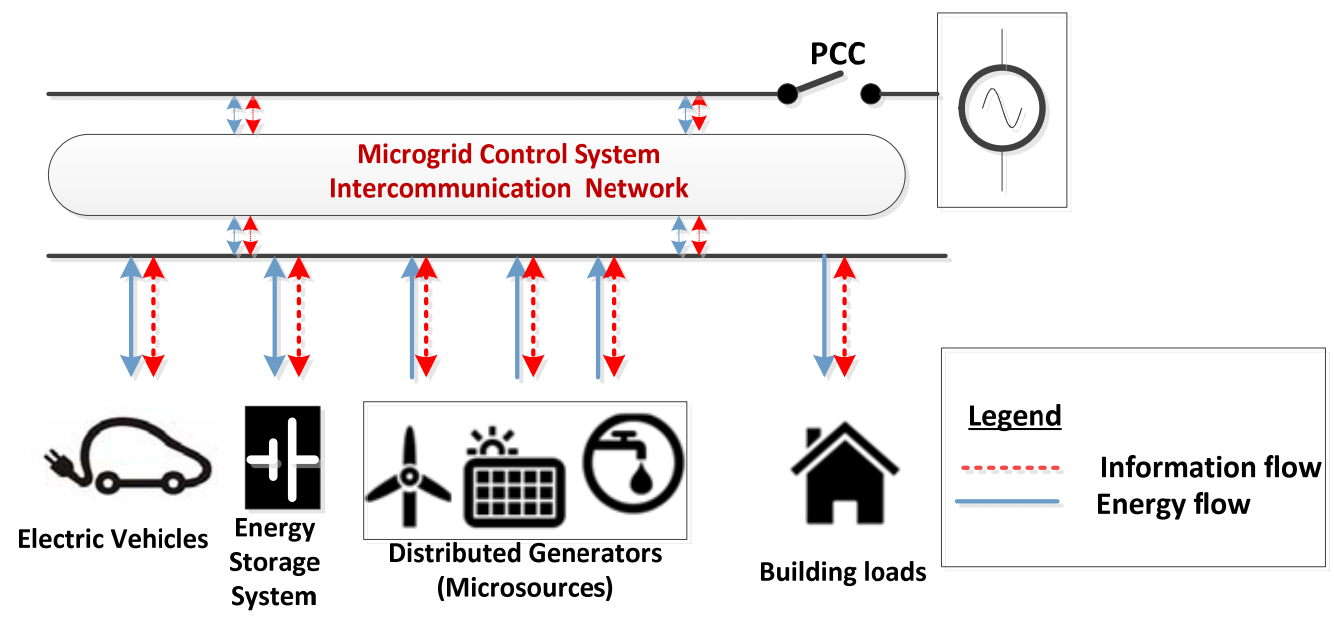

Fig.1. Simplified scheme of a microgrid with a Microgrid Controller

Traditionally, this control is carried out by means of a three level hierarchical scheme [7], [8]: (Figure 2): Distribution Management System or tertiary control (DMS), Microgrid Central Controller (MGGC) or secondary control and load control (LC) or primary control [5], [6], [9].

- Primary Control: This level of control operates in the time range of milliseconds to minutes, and reacts to the transient dynamics of the DER and the system to respond to any instantaneous deviation in the system's voltage or frequency. This controller acts as local control for each DER unit and utilizes local measurements and responds to short-term events such as islanding detection, sudden real and reactive power mismatches, and power sharing.

- Secondary Control: This level of control operates in the time range of minutes to hours, and it comprises the discrete dispatch of DER. This level is controlled by the MGCC. This controller is responsible for the optimal coordination and operation of the whole components connected in the same microgrid, assuring the overall maintenance of the grid parameters in both connected and island mode. The secondary control also incorporates control strategies and operations such as intentional islanding, resynchronization, and load shedding. 
- Tertiary Control: This level of control operates in the time range of hours to days, and it involves the communication with the different microgrid central controllers (MGCCs), and management of the MG when it operates on the market. The main entities in this level are the Distribution Network Operator (DNO) and the Market Operator (MO) who are delegates of the main grid.

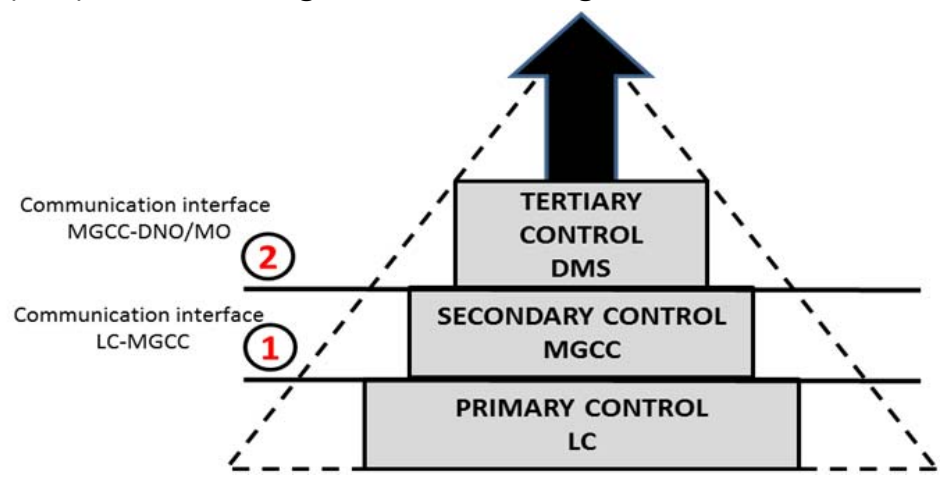

Fig.2. General Hierarchical Architecture of MG control. Communication interfaces for stablishing MG control.

Control strategies need communication networks or links between the different levels to achieve an optimal microgrid operation. Communication interfaces must be created to establish a bi-directional communication channels that allows information transfer between the different controllers [10]. (Fig.2, (1) and (2)). Generally, data flows between nodes in both directions, i.e., each node are able of receiving and forwarding data over links with other nodes or endpoints. The nodes in microgrids are created by adding information and communication capabilities to the underlying distributed energy resource or component, giving rise to intelligent electronic devices (IEDs) [11]. In this way, the microgrid controller may communicate with IEDs and other components to provide them data or control commands.

For a successful information exchange between nodes within a microgrid system, predefined procedures or protocols for data transmission regulation are needed. A protocol suite consists of a layered architecture where each layer is assigned to a set of functions using one or more protocols [11]. Data communication networks commonly use multiple levels of protocols based on ISO-OSI (International Standards Organization/ Open Systems Interconnect reference) model [12] (seen Figure 3). This allows to convert the information in a form that can be transmitted. Thus, regarding communications, the effectiveness of the control and the communication microgrid infrastructure is linked with the microgrid control scheme and its communication architecture. 
OSI

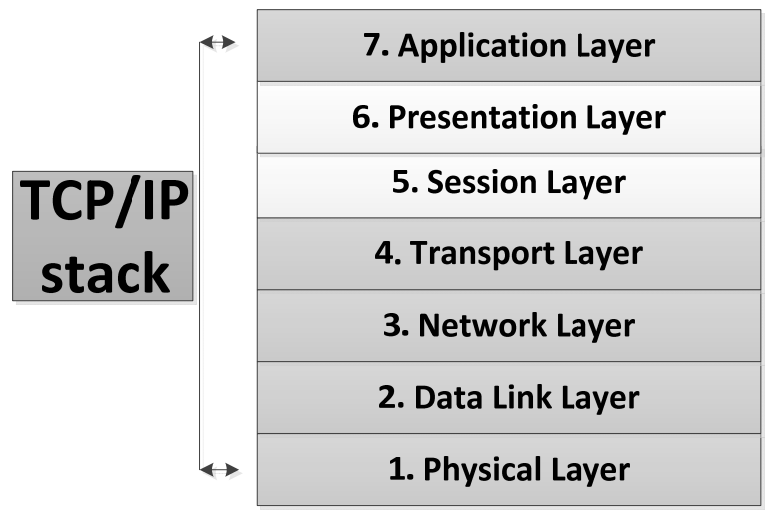

EPA Model

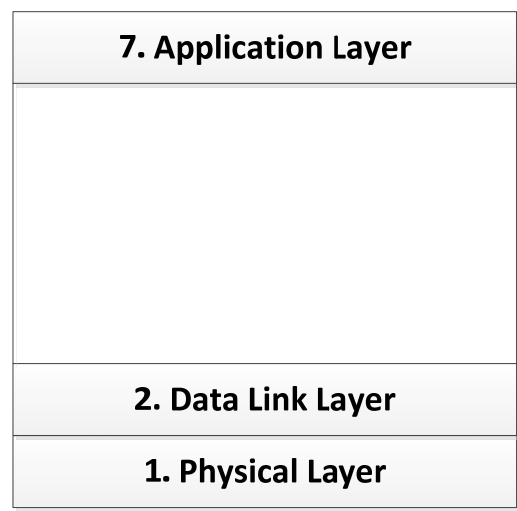

Fig. 3. OSI Reference Model, EPA model and TCP/IP model

Today's microgrid installations use centralized architectures to implement the three level hierarchical scheme and achieve data transfers between entities. In these architectures power is delivered in a unidirectional way and consumers have a passive role characterized by noncontrollable loads, lack of predictability and null contribution to the system management.

These centralized architectures where a central controller communicate with all microgrid resources and make decisions has been implemented, for many years, by Supervisory Control and Data Acquisition (SCADA) systems [13] which uses the Enhanced Performance Architecture (EPA) model [11] . EPA has three layers $(1,2$ and 7$)$ instead of the seven layers defined in the OSI model as depicted in figure 3. This fact reduces the services offered by the EPA stack protocol. Otherwise, SCADA use direct communication links (i.e. no internet) [11] to send and receive commands and data through various protocols. Some of the most popular protocols in the electrical sector are MODBUS, PROFIBUS, CANBus or DNP3. All of them are generally based around Client-Server (Master-Slave) architectures with bus network topologies, [11], [14], [15].

Recently, there is growing a trend towards the use of new communication technologies based on internet or on Common Information Model (CIM). The Internet architecture is based on TCP/IP protocol. TCP/IP is an easy solution to the problem of achieving end-to-end communications [16]. TCP/IP protocol suite is used by Internet. The TCP/IP stack normally has four layers: Physical and Data Link layer (Link layer), Network, Transport and Application layers [Figure 3, TCP/IP stack]. These protocols are now starting to be used in electrical control systems and it is evidenced by the evolution of the Industrial Protocols, that were previously cited, such as Modbus, DNP3 and Profibus towards Modbus/TCP, DNP3 over TCP and Profinet, respectively, for their integration on the traditional SCADA. These protocols exploit the benefits of TCP/IP to upgrade their capabilities. For instance, in the case of Modbus or Profibus over TCP/IP communication systems, they are reported undesirable events as incorrect address, packet failure, illegal function code received, etc. Besides the aforementioned properties, DNP3 over TCP/IP supports timestamps and data quality information that can be included in the messages [11]. However, despite these improvements, the centralized control based in client-server communication architectures cause inefficiencies in the communication microgrid system, provoked by several causes: On one hand, a failure in the centralized control point could lead on several faults or even shut down the entire system. On the other hand, the nodes (slaves) are not able to start a communication themselves with the master. In 
addition, there are difficulties to manage data in real time of a wide range of devices [17], [18]. As a result, these disadvantages can lead to provide poor services, bottlenecks or underutilization of the network resources.

An alternative technology to be used in microgrids is Power Line Carrier (PLC). PLC technologies use the electric power lines as a medium that enable the bidirectional data exchange. It provides a vast coverage and in terms of infrastructure is the most cost-effective technology since the lines already exist. In recent years, microgrids activities have brought a lot of attention to PLC technologies. As an example, the microgrids installed in the University of Seville and NUAA in China, uses PLC as a communication medium for information management and transmitting data [19] . However, PLC technology has negative effects in the communication channel such as a noisy medium disturbed, distortion, frequency impedance alterations and the risk of signal attenuation [20].

The increasing introduction of distributed energy resources into the power grid changes the current scenario, because the incorporation of micro-generation allows bidirectional power flows and active consumers, i.e., the end users change their role of passive consumers to active prosumers. Consequently, immediate solutions about microgrid communication architectures that cope with these changes and enable high performance data delivery and real-time monitoring and control are needed, leading to reliable, resilient and sustainable microgrid control systems.

\section{TOWARDS AN INTELLIGENT MICROGRID}

It has been noted that communication system used in today's microgrid has important inefficiencies and it is also localized to support the integrated communications needed for the modern power grid (smart microgrid (SMG)). However, energy systems are increasingly distributed. The integration of DERs into the energy system cause many challenges into the communications field. To incorporate more renewable and alternative energy sources, the communication infrastructure must have the ability to easily handle an increasing amount of data traffic or services requests and must provide a real-time monitoring and control operation of all these nodes. Current serial communications deployed in SCADA systems refer to a set of legacy standards that are still used for low data rate applications and asynchronous bit transfer. Since microgrid operations need timely control actions, a Real-Time Measurement Parameters (RTMP) function is required [21]. To reach this goal, it's mandatory to know which bandwidth and which latency (delay) can tolerate each microgrid application [22], [23], i.e., each microgrid function has its own latency and bandwidth requirement depending on the kind of system response it's dealing with [12], [24], [25]. The IEC 61850 and IEEE 1646 standards [26], [25] give specifications for these requirements. The network performance requirements for each microgrid application have been summarized in Table 1. Moreover, the expected communication delay of each kind of microgrid message was specified in [27], being summarized in Table 2. 


\begin{tabular}{lll}
\hline Microgrid Messages & Bandwidth & Latency \\
\hline Demand Response & $14-100 \mathrm{Kbps}$ & $500 \mathrm{~ms}-\mathrm{several} \mathrm{minutes}$ \\
Distributed Energy Resources and Storage & $9.6-56 \mathrm{Kbps}$ & $20 \mathrm{~ms}-15 \mathrm{~s}$ \\
Distributed Management & $9.6-100 \mathrm{Kbps}$ & $100 \mathrm{~ms}-2 \mathrm{~s}$ \\
\hline
\end{tabular}

Table 1. MG application and network requirement

\begin{tabular}{ll}
\hline Microgrid Messages & Delay Requirements \\
\hline Protection information & $4 \mathrm{~ms}$ \\
Monitoring information & $1 \mathrm{~s}$ \\
Control information & $16 \mathrm{~ms}-100 \mathrm{~ms}$ \\
Operations and maintenance information & $1 \mathrm{~s}$ \\
Messages requiring immediate actions at receiving IEDs & $1 \mathrm{~A}: 3 \mathrm{~ms}$ or 10ms;1B: $20 \mathrm{~ms}$ or $100 \mathrm{~ms}$ \\
Continuous data streams from IEDs & $3 \mathrm{~ms}$ or $10 \mathrm{~ms}$ \\
Synchronization messages & (Accuracy) \\
\hline
\end{tabular}

Table 2. Microgrid Message Type Delay Requirement for different microgrid functions (from [27]).

The communication infrastructure in the microgrid must satisfy these timing requirements, because a low bandwidth can lead to bottlenecks, loss of data packets and distortion. Besides, if the communication delay exceeds the required time, the information does not fulfill its purpose and, in the worst case, electric damage in the microgrid could happen [4]. In this regard, the underlying communication system needs to be designed with network performance requirements to meet the needs of time sensitive data streams, bandwidth and latency, among others. To satisfy this network performance requirements that smart microgrid traffic requires, Quality of Service (QoS) is needed. The Quality of Service concept is the network ability to provide priority treatment for communication packets of certain critical microgrid applications. QoS management is needed for distributed control and protection microgrid applications that have severe delay requirements and need to deliver information in an acceptable amount of time. For instance, the stability of the closed-loop while performing bilateral load following (with sampling rates typically in the range 100-1000 $\mathrm{ms}$ ) is highly dependent upon the latency (delay), variability in latency (jitter), and packet losses that the control network induces [28]. Therefore, when networks exceed their capabilities to transfer, store and buffer data, packet loss and low delivery rates are experienced. As a result, when the network faces congestion due to dense data traffic, QoS allows a preferential delivery service for the most critical applications by ensuring sufficient bandwidth, latency and reducing data loss. QoS information is stored within the packet header in the form of a type of service (ToS) field to specify the class of service of each packet. Thus, based on the ToS byte, if there is a packet in a high priority queue, it's served before the packets in low priority queues.

Besides, the increasing number of renewable energy sources and microgenerators as well as the integration of a large amount of DER units in the microgrid has an impact on the scalability of the communication system [8]. The main problem regarding the control of a wide number of DERs is that a failure of a device or a software error could bring down the entire system [29]. Furthermore, in networks with a high volume of devices is usual to add/remove devices to/from the network very frequently, therefore networks must be flexible enough, allowing the fluctuations of the number of devices and avoiding disturbances or instabilities. To cope with these potential failures, the system requires a certain level of redundancy, e.g., backup channels, software components and devices, etc. Critical functionalities in a smart 
microgrid demand more stringent availability requirements. It is worth pointing out that most network service providers (NSP) applications require less than $99.99 \%$ uptime, compared with 99.9999\% for smart grids [20]. To achieve reliable and robust networks, the communication infrastructure must avoid link errors, routing problems, overloads, etc. Current SCADA systems cannot make these data available in a timely manner due to their limited bandwidth [30]. Thus, this capability requires the combination of advances in computational and analytical methodologies and self-healing protocols. In this context, Software Defined Networking (SDN) has emerged as a flexible, effective and reliable communication framework and as a power solution for the future communication network of the energy internet [31], [32]. This solution provides support for the dynamic, scalable computing and storage needs of complex digital networks by software and allows adaptive control and operations of networks in a cost-effective manner. These characteristics are favourable for developing hierarchical communication network architectures which allow to decouple control plane (which decides how to handle the traffic) from data plane (which forwards traffic). Moreover, SDN allows selfhealing and self-organization [33] required features for the future smart microgrid developing.

The integration of networking and communication technologies in microgrids may cause vulnerabilities of cyber attacks. In addition, due to the increase number of distributed energy resources in the grid, the attack targets are also rising, producing more access points to disrupt the grid [34]. Thus, a microgrid needs to be robust against security attacks. To guarantee a proper protection, it's necessary to minimize the 'attack surface' and to decrease the security detection response time, increasing the amount of effort required to violate the network in order to guarantee a proper protection [35]. The security architecture for SMG communication networks should be divided into different levels and zones such as device level (e.g. recovery from attacks), system level (e.g. access control, authorization, encryption, authentication, ...) and organization level (e.g. policies, mechanisms, ...). As a result, protocols should be designed and adopted by the communication system in order to identify and correct weaknesses in their physical and cyber security parameters.

In conclusion, the implementation of smart microgrid concept and its optimal and efficient control architecture become a necessary for integration of a high volume of DER. For achieve that, the intelligent microgrid requires information and communication technologies. However, despite the urgent need to materialize the intelligent microgrid there are several challenges should face to ensure this new communication architecture addresses: i) Real-time operation and network performance requirements such as latency, bandwidth and QoS mechanisms, ii) Reliability: flexibility and availability to manage a large amount of DER, iii) Cybersecurity issues

\section{DECENTRALIZED GENERATION IN MICROGRIDS}

To evolve towards development of smart microgrids satisfy the requirements above mentioned in Section 3 is mandatory. For reaching these objectives, the grid should move from a centralized infrastructure to a decentralized one. The decentralized communication infrastructures remove the centralized controller as a single point of failure and therefore produce an improvement in the reliability of microgrids. In this structure all devices are able to 
control themselves independently as opposed to a "master" controller, i.e. each DER unit is considered as an agent. An agent is a computer system able to do tasks on an autonomous way and with capabilities to communicate with their neighbor nodes for solving problems through cooperation, coordination and negotiation [36]. As a result, the centralized hierarchical management scheme presented on Section 2 could be implemented employing a decentralized architecture. This section presents relevant distributed communication topologies, communication technologies and protocols to tackle the design of a communication distributed architecture for a microgrid.

\subsection{Distributed Communication Network Topologies for Smart Microgrids}

Nodes or agents network topology in decentralized architectures is crucial in terms of developing an efficient and appropriate microgrid. According their logical topology and degree of decentralization, distributed networks can be broadly classified into the following architectures [36], [37] , [38], [39] (Figure 4):

- Centralized: This topology uses a central server node to store nodes resources and information as well as act like an agent to coordinate actions among theirs. Nodes send messages to the central server to determinate the addresses of nodes that contain the required resources/data. However, like a decentralized system, once a node has the information, it can directly communicates with the searched node without help of the central server. In this structure, the agents have an increased intelligence (compared with typical nodes of the communication network) and improved communication capabilities. Additionally, some control tasks are distributed through agents, although they still have a lack of decision-making capabilities. Moreover, centralized distributed topologies still have a unique point of failure, scalability limits, performance degradation and lack of robustness.

- Hierarchical: This topology is characterized by having some agents (super nodes) that take authority over the actions of other agents. In this network exists various agents that carry out different hierarchical tasks. Most microgrid deployment in literature employs a three-level hierarchical architecture where, generally, top -level agents are responsible for critical decisions, middle-level agents make decisions about connected or disconnected grid tasks and the lower-level agents interact with sensors and devices. The choice and allocation of these super nodes is dynamic. This approach is still unreliable due to not all peers can act as super-nodes by a lack of resources.

- Distributed: In a distributed communication topology, each local agent is autonomous, has the same role in the network and is responsible for acquire knowledge about its own part of the network. A significant difference regarding the other architectures is that individual agents are allowed to discover other agent information through communication and coordination with their neighbors. This topology do not uses a central server to manage the network avoiding a single point of failure and allowing a very high scalable network. 


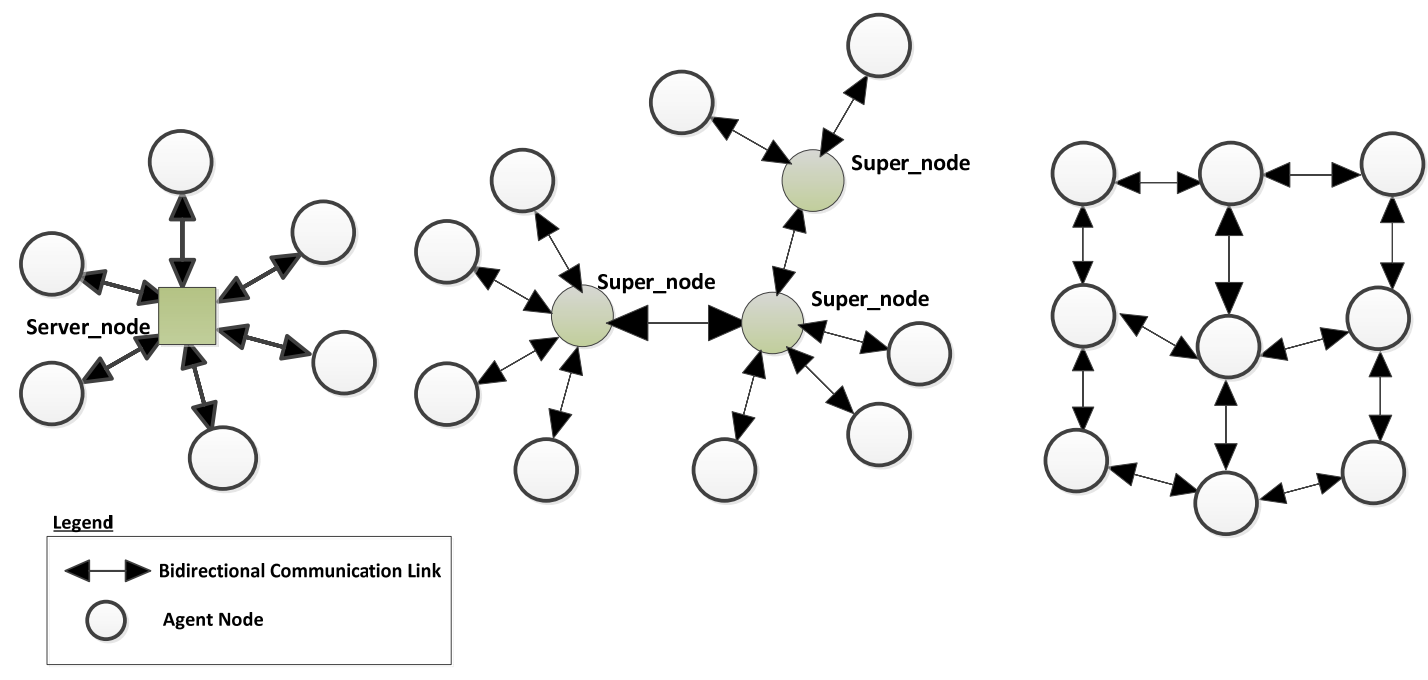

Fig.4. Decentralized architectures for microgrid control: Centralized, Hierarchical and Distributed.

The selection of the appropriate network topology has have an important impact on the information flow, on the performance and on the capability of the microgrid network to be expanded and updated. Fully decentralized topologies present several advantages among the others, as it's been described above. Distributed centralized topologies are acceptable in microgrids where a pre-defined operator manages the microgrid and the generation and consumer sides of the power system have similar goals. The central server receives status information from all the units and can calculate an optimal global control strategy, providing a practical implementation of the control infrastructure and reducing the implementation costs. Nevertheless, decentralized control is the most suitable method when there are multiple energy devices on the generation and consumption sides to be managed, requiring real-time monitoring and adjustment. In this case, a centralized control could not meet the requirements. Although the installation costs of decentralized control topologies are higher than those of centralized control, the operation costs are greatly reduced and it can be amortized in a short time [40]. In addition, in decentralized networks it's possible to install modular and scalable systems with a good precision.

\subsection{Distributed Communication Technologies for Smart Microgrids}

A distributed network is a collection of nodes placed at remote locations over a geographical area and connected through communication links for data transmission among the agents under operation. A link may be realized by means of different communication technologies supported by two main communication media, wired and wireless. The choice of the communication medium technology has its associated advantages and disadvantages that designers should evaluate. Therefore, one key aspect of smart microgrids communications design is to deploy suitable and future-proof wired/wireless technologies.

Traditionally, wired communications have been employed to transmit information through the electrical grid due to their better performance than wireless technologies regarding robustness, reliability, security and bandwidth properties. However, wired technology involves higher deployment cost. In addition the network expansion schemes become more complex. Some popular wired technologies used in microgrids are serial 
communication RS-232/422/485 for SCADA systems [23], Ethernet (IEEE 802.3 technology), bus based technologies (e.g. ModBus, ProfiBus) and Power-Line Communication (e.g. DLC, PLC, BPLC) [41]. However, except of Ethernet, these technologies cannot provide decentralized communications in a reliable manner. The possibility to implement Ethernet over microgrid systems were reviewed very recently by [42], [43]. These works demonstrates Ethernet's applicability for DER's data exchange allowing share bandwidth to all connected devices and it demonstrates that Ethernet can be used in a real time as well as a great scale.

By other side, in spite of their (in general) lower performance in terms of robustness, the wireless technologies are increasing their security capabilities and could be an interesting solution for distributed microgrid communication links because of the cheaper installation costs. Depending on the network coverage, distinct groups of wireless network technologies can be identifies: WPAN (Wireless Personal Area Network), WLAN (Wireless Local Area Network), WMAN (Wireless Metropolitan Area Networks) and WWAN (Wireless Wide Area Network). The most popular solutions for wireless internet access in microgrids are [44]: Family standards IEEE 802.15 (Wireless Personal Area Network, WPANs), especially IEEE 802.15.4 standard (Low-Rate Wireless Personal Area Network, LR-WPAN) that defines the specification for low rate, low power, low complexity and short ranges or IEEE 802.11, Wi-Fi (WLANs). They are networks to cover small amounts of information over relatively small distances. Both technologies could be used to perform the links either between DERs at primary level and/or between DERs and MGCC at secondary level on the hierarchical microgrid control scheme. By other side, cellular networks (4G/3G/HSPA, LTE (Long-Term Evolution), LTEA (Long-Term Evolution Advanced), and Evolution-Data Optimized) could be used for implementing links at tertiary level and/or between different microgrids [45].

The Wireless technologies listed above provide communication between nodes in a single hop. However, multi-hop technologies may be assumed a key function in microgrid network control research due to they allow to extending the coverage of a wireless network over multiple wireless hops. Mobile Ad-hoc Networks (MANETs) or Wireless Mesh Network (WMNs) are wireless multi-hop networks. An ad-hoc network is a collection of independent nodes that communicates without infrastructure support using wireless links. In this networks nodes operate as both host and routers, in other words, can act as a router to transmitting data of its nodes. Similar to the MANETs are WSNs that have been created to resolve limitations as well as improve the performance of WPANs, WLANs, WMANs, WWANs and MANETs in general [46]. These are networks composed with multiple Mesh Access Points (MAP), usually stationary points, that create mesh topologies whose aim is provide access to different infrastructure networks [47], for example clients in ad-hoc network operating in WI-FI network cannot access in a different radio technology network such as WPANs or other networks, while in case of WMNs both network access are possible through mesh routers. This characteristic is very important in order to achieve interoperability between microgrids. Examples of this kind of microgrids have been study in [48], [49], [50], [51]. This reviews determined that mesh networks offer higher levels of redundancy and robustness in terms of data communications in case of link degradation, failure or loss of node, either temporary or permanent very important characteristics for microgrids deployments. Multiple hops can be used to achieve a more balanced distribution of traffic over network [52], [53]. In fact, the wireless technologies 
presented before, are now including support for multiple-hop communications which is the case of the IEEE 802.15.4g (mesh network solution for smart metering) [54], IEEE 802.15.5 (mesh network for WPANs/ZigBee) [55] and 802.11s (networking capabilities to Wi-Fi) [56]. It is important to point out that exists the possibility to use this technique in cellular networks (4G or LTE) to achieve increasing the coverage or the capacity in the cell [57].

\subsection{Main Distributed Smart Microgrids Networking Protocols}

To allow communications in a distributed network it's essential to specify the set of protocols to be implemented in each node. The decentralized communication networks used in microgrids are focused on the implementation of suitable Transmission Control Protocol/Internet Protocol (TCP/IP) [58]. Current TCP/IP based communication systems provide a high enough bandwidth and real time monitoring and control of smart microgrids. Moreover, smart microgrids can deploy their "utility-Intranet" to obtain full control on communications with increased flexibility, security and reliability. The design of a client-server architecture for power grids using TCP/IP for information transmission has been discussed in [59], [60]. For communication between two endpoints a protocol stack development is mandatory. In this section, the main layered protocols that could be used to deploy distributed smart microgrids are described. Figure 5 depicts both the main communication purpose at each layer in the TCP/IP protocol stack and the main networking protocols used in a Microgrid Control System.

\begin{tabular}{|c|c|c|c|c|c|c|c|}
\hline \multicolumn{3}{|c|}{ TCP/IP MODEL } & \multicolumn{4}{|c|}{ STACK PROTOCOLS } & \multirow{3}{*}{$\begin{array}{c}\text { Security } \\
\text { Protocols } \\
\text { TLS/SSL, } \\
\text { DTLS, SRTP }\end{array}$} \\
\hline $\begin{array}{l}\text { Application } \\
\text { Layer }\end{array}$ & $\mathbf{L 5}$ & $\begin{array}{l}\text { Process-to-Process } \\
\text { Communication }\end{array}$ & \multicolumn{4}{|c|}{ Multiple Applications } & \\
\hline $\begin{array}{c}\text { Transport } \\
\text { Layer }\end{array}$ & L4 & $\begin{array}{l}\text { Host-to-Host } \\
\text { Communications }\end{array}$ & \multicolumn{3}{|c|}{ TCP/UDP } & & \\
\hline \multirow{2}{*}{$\begin{array}{l}\text { Network } \\
\text { Layer }\end{array}$} & \multirow[t]{2}{*}{ L3 } & \multirow{2}{*}{$\begin{array}{l}\text { Inter-Network } \\
\text { Communications }\end{array}$} & \multicolumn{3}{|c|}{ IP (IPv4,IPv6) } & $\begin{array}{l}\text { Zigbee } \\
\text { RF-mesh }\end{array}$ & \multirow{2}{*}{ IPsec } \\
\hline & & & & Qos Me & (MPLS) & & \\
\hline Data Layer & $\mathbf{L 2}$ & Link Establishment & Ethernet & $\begin{array}{l}\text { POS } \\
\text { PPP }\end{array}$ & $\begin{array}{l}\text { RLC } \\
\text { MAC }\end{array}$ & \multirow{2}{*}{$\begin{array}{c}\text { IEEE } \\
802.15 .4\end{array}$} & \multirow[b]{2}{*}{ MACsec } \\
\hline $\begin{array}{l}\text { Pyshical } \\
\text { Layer }\end{array}$ & $\mathbf{L 1}$ & $\begin{array}{c}\text { Physical } \\
\text { Communication } \\
\text { Medium }\end{array}$ & TDM & $\begin{array}{l}\text { SONET } \\
\text { WDM }\end{array}$ & $\begin{array}{l}\text { LTE } \\
\text { OFDM } \\
\text { MIMO }\end{array}$ & & \\
\hline
\end{tabular}

Fig.5. Communication and security common microgrid protocols stack in the TCP/IP model

Link Layer: This layer describes the operational physical and data link network functions. The Physical Layer (L1) is the medium used for the transfer of data. The Data Layer (L2) is used to establish a link between two nodes. As described before, distributed smart microgrids accept different communication technologies, wired and wireless. Regarding wired technologies, the control systems implemented in microgrids generally use the Ethernet protocol (IEEE 802.3) for fast and reliable operation, but the cost to develop this kind of network is expensive for long distance communications. Typically, the Ethernet protocol is coupled with the Medium Access Control (MAC) protocol, a sublayer of the L2 link layer. The MAC sublayer, in addition to the receive and transmit data frames, assigns addresses to each connected microgrid device. Commonly, these type of wired networks (coaxial cable or twisted pair) uses TDM (Time 
Division Multiplexing) as L1 protocol. TDM is a digital processing method that allows to share the total bandwidth among different connections. This is achieved through putting multiple data streams in a single signal by separating the signal into many segments, each one having a very short duration.

In smart microgrids over fiber optic networks, WDM (Wave Division Multiplexing) or SONET (Synchronous Optical NETwork) also called Synchronous Digital Hierarchy (SDH) are the protocols used in L1. WDM is a method which combines multiple signals on laser beams at various infrared (IR) wavelengths for their transmission along fiber optic media. Besides, SONET is a high data rate protocol (up to $40 \mathrm{Gbps}$ ) originally developed for voice communication over optical fiber networks. The L2 protocol for SONET is typically 'Packets over SONET'/SDH (POS). POS employs the Point-to-Point Protocol (PPP), a common L2 protocol used to establish a direct connection between two nodes that can simultaneously support multiple L3 network protocols including TCP/IP. The use of fiber optic technologies can multiply the effective bandwidth of a fiber optic communications system by a large factor, but its cost must be studied for its implementation in microgrids against the alternative of using Ethernet technologies into a cable [61], [62], [63]. Nowadays, the use of Ethernet in LAN is very common and has evolved to support high data rates over long distances, such as metropolitan area networks (MAN).

Recent advances in wireless communications with easy installation, low cost and acceptable transmission speed make this technology be viable for microgrid monitoring and control. For their implementation, two protocols can be used. L1 protocols, such as LTE, are used when they run on fourth generation cellular networks (4G). Protocol 802.14.5 is the common choice when ad hoc communication networks composed of radio nodes are used. LTE uses an L1 protocol called orthogonal frequency-division multiplexing (OFDM) to enable simultaneous two-way communications. LTE also employs multiple input and multiple output (MIMO) to multiply the capacity of individual radio links by using multiple transmit and receive antennas to exploit multi-path propagation of signals. L2 layer in cellular networks, LTE has a MAC sublayer that acts as interlinking with the RLC (Radio Link Control) sublayer that performs packet segmentation and flow control among entities. RLC also supports end-to-end IP connection. The L2 layer for ad-hoc networks support Radio Frequency Mesh (RF-mesh) such as IEEE $802.15 .4 \mathrm{~g}$ or IEEE 802.15.5. For smart microgrids applications the predominant RFmesh standard is Zigbee (IEEE 802.15.5). Zigbee enhances the IEEE 802.15.4 standard by adding networking and security functions required for smart microgrid applications.

Additionally, in Section 3 it's been pointed out that a communication infrastructure with Quality of Service (QoS) requirements is absolutely needed. Consequently, microgrids should adopt suitable mechanisms to guarantee QoS. In telecommunication networks, QoS differentiation is achieved through resource reservation and traffic prioritization [20]. These characteristics are implemented at a "layer 2.5" protocol, as it performs the functions of L1 and L2 while also including features that are typical of L3. For carrying out QoS implementation in communication networks, many families of standards define the medium access control (MAC) layer with the specification of different traffic categories. However, Internet by itself cannot assure QoS requirements, because the best-effort level of service for the delivery of data is the rule in today's Internet [64], [65]. Therefore, traffic handling 
mechanisms must be implemented in microgrid networks at "2.5 layer", using protocols such as Integrated Services (Intserv), Differentiated Services (Diffserv), Multiprotocol Label Switching (MPLS), IEEE 802.1p/q tags (QoS mechanism on Ethernet) and IP Precedence [66], [67]. These several QoS services allow a single network to satisfy different types of traffic by emulating many L1 and L2 protocols including T1, PPP, Frame Relay, and Ethernet.

Internet Layer: The Internet Layer (L3) controls the operation of packet transmission by assigning addresses to nodes and routing frames along physical paths. The Internet Protocol (IP) is the most widely implemented networking layer protocol. Although the Internet is based on IP, the protocol is also used on networks unrelated to the Internet. IP enables end-to-end smart microgrids applications to communicate to any two endpoints that have at least one or more networks providing a data path between them by using various networking technologies, i.e., IP can operate independently of the underlying physical media, L1 and L2 layers. This characteristic provides interoperability among third-party non-compliant end devices and compliant communications networks. This allows much greater flexibility for interoperability as utilities implement their Smart Microgrid network. Therefore it plays a vital role in unifying the information while allowing utilities to select the communications technologies and end devices (meters, IEDs, etc.) that make the most sense for them. Network interoperability is indispensable in order to achieve an overall optimal system operation and connectivity, independent from the used physical medium, the type of devices and the manufactures [68].

IP is available with either of two versions (IPv4 and IPv6). In both versions, every system (node or endpoint) is identified by its unique network layer address, but the main difference between both IP versions is their respective host addressing systems: IPv4 uses 32-bit, whereas IPv6 uses 128-bit addresses. However, the version of IP currently deployed in most microgrid networks is IP version 4 (IPV4). Despite of this, microgrid network planning should consider future migration to IPv6, because the distributed energy resources (DERs) in the grid may need their own individual IP-address in the future. Currently, many investor-owned utilities have millions of electric meters installed. Other devices must be additionally considered, including an important amount of electric vehicles as potential roaming users in the future. That means that IPv4 might not have enough IP addresses for each of these large number of endpoints [69]. Additionally, multicasting is supported by IPv6 and introduces new features to QoS capabilities [70].

Transport Layer: The transport protocols (L4) enable host-to-host communications. The two most common transport layer protocols are the Transmission Control Protocol (TCP) and the User Datagram Protocol (UDP). TCP is a connection-oriented protocol that provides reliable, sequenced, and error-checked delivery of a stream of packets between application endpoints. TCP is optimized for accurate and reliable delivery of packets rather than timely delivery, thus yielding relatively long delays. UDP is not connection-oriented, not providing any guarantee on packet delivery, but is highly time-sensitive [71]. The choice of the best suited protocol within a microgrid control system network depends mainly on design requirements based on the importance of speed versus reliability and on the need for error detection [11]. However, since the microgrid application requires reliable communications, TCP is the best option to be implemented [59]. On the contrary, shortcomings of TCP in performing congestion control for a large number of data sources and its inherently delayed acknowledgement could be 
ineffective for SMG control which can produce useless retransmissions of packets and throughput degradation [20], [60]. As a consequence, a large number of transport protocols and mechanisms have been proposed in order to improve the transport services offered to applications and to optimize the usage of the different technologies. For example, SCTP (Stream Control Transmission Protocol) and DCCP (Data Congestion Control Protocol) have been proposed to support the nodes mobility in the network [72] but these protocols are insufficient to address the transport characteristics of the nodes in the microgrid due to some intermediate nodes or Network Address Translation (NATs) may be not fully aware about these protocols (at the network level), which could lead to a blocking packets at the processing [73] and therefore a sub-optimal microgrid operation. These problems have motivated researches about development of novel protocols for their application in microgrids. Some of these are: SSTP (Scalable Secure Transport Protocol) and MPTCP (Multi-Path Transport Protocol) [74], [75], [76] that have been customized for grid data collection. By other side, for enhancing performance network mechanism, TCP-splitting is, nowadays, the most used approach in microgrids [60].

Application Layer: The application layer (L7) contains the protocols that support process-toprocess communications, i.e. serves as the network interface for users and applications. It contains a variety of common functions such as resource sharing, remote file access, directory services, electronic messaging, etc. For microgrid network management, common application protocols like Dynamic Host Configuration Protocol (DHCP), Domain Name Service (DNS) or Network Time Protocol (NTP) can be used. Also specific protocols such Distributed Network Protocol (DNP3), Modbus, Profibus over TCP/IP or proprietary vendor specific protocols could be used [71]. However, for reliable and scalable communication architecture, interoperability is needed. In the field of the Microgrid, international standards have defined for achieve these interoperability at application layer. The most important of them are listed in table 3.

\begin{tabular}{lll}
\hline Reference Standards & Detail & Application \\
\hline $\begin{array}{lll}\text { IEC 61850 (61850-7-420) [77], } \\
\text { [78] }\end{array}$ & $\begin{array}{l}\text { Communication between devices in transmission, } \\
\text { distribution and substation automation system }\end{array}$ & DER/microgrid \\
IEC 61968 [79] & $\begin{array}{l}\text { Data exchange between device and networks in the } \\
\text { power distribution domain }\end{array}$ & $\begin{array}{l}\text { Energy management } \\
\text { system }\end{array}$ \\
IEEE 1547.x [80], [81] & Interconnecting DERs with Electric Power System & DER/microgrid \\
IEEE 1646 [82] & Communication Requirements & Substation Automation \\
\hline
\end{tabular}

Table 3. International Standards for MGs Networking/ Communications

The IEC 61850 is the most promising standard for design power communication networks [83], [84]. This standard has been proposed to increase the reliability and availability and to ensure interoperability. This standard use a communication model based on protocols such as Manufacturer Message Specification (MMS) for communication messaging, Simple Network Time Protocol (SNTP) for time synchronization and Generic Object Oriented Substation Events (GOOSE)- Sampled Measured Values (SMV) for fast messaging. It can operate over TCP based on implementing Ethernet [85]. The communication stack mapping the IEC 61850 services with the TCP/IP model layer is shown in Figure 6. 


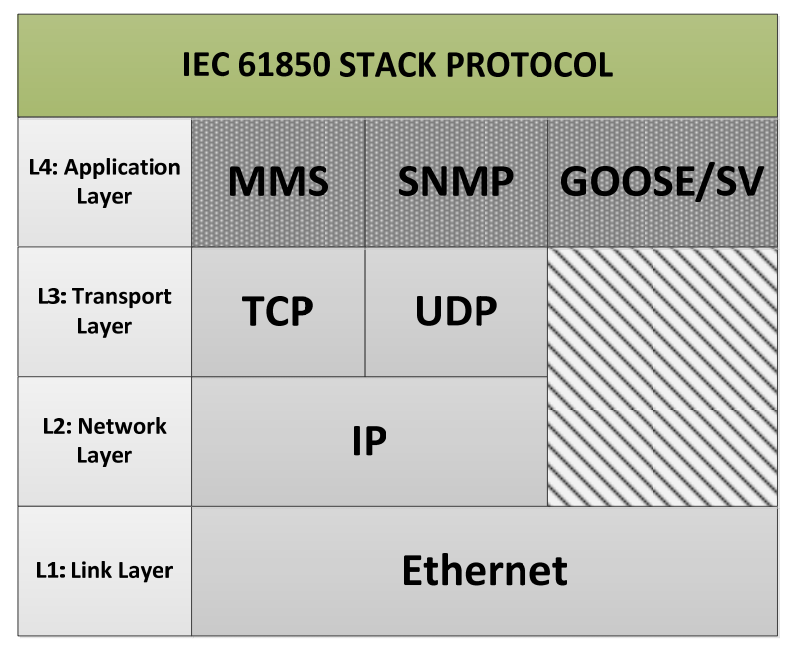

Fig. 6. Typical IEC 61850 Ethernet-based communication TCP/IP stack.

Security Protocols: A microgrid control system network, apart from cyber-security mechanisms to prevent attacks, need protocols to provide network security (such as authentication and encryption). Security Protocols have to be end-to-end, lightweight, and scalable and prepared to be added at any layer to protect data transmitted between different microgrid applications and host. There are many end-to-end security protocols that can apply to microgrids networks and they can run over IP to ensure end-to-end security communications [35], [86], [87], [88]. Some security protocols are: Internet Protocol Security (IPsec), Transport Layer Security/Secure Sockets Layer (TLS/SSL), Datagram Transport Layer Security (DTLS), Secure Shell (SSH) Protocol or Secure Real-Time Transport Protocol (SRTP). These protocols have been used for microgrids security; however, for achieving a good level of security, the access of unauthorized nodes to the network information must be prohibited. A good option would be the use of MACsec [35]. A protocol that provides hop-by-hop security, so each node in the path has to verify the integrity and authenticity of the message in the reception block, and regenerate the MAC in the transmission block [35].

This stack of protocols for deploying decentralized smart microgrids networks is most often implemented through a MAS technology (Multi-Agent System). In fact, the IEEE Power Engineering Society Intelligent Systems Subcommittee created the group the IEEE Power and Energy Society Multi-Agent Systems Working Group (MASWG) for defining the correct use of the MAS technology within the distributed power grid domain.

MAS consists of multiple intelligent agents that interact to solve problems through cooperation, coordination and negotiation. These agents can be structured forming fully decentralized topologies, where in each one of them the TCP/IP stack protocol is implemented to give them fully networking operation. Several papers have specially applied MASs to microgrids [89], [90], [39], [91]. However, the increasingly distributed and intelligent energy systems along with their multi-disciplinary nature yield such a big data volume that the management and control of microgrids is becoming a critical challenge. The latest research indicates that distributed MAS architectures have some limitations on the efficient and optimal management of these emerging microgrids [92], [93], [94], [95], [96], which are described below: 
1) MAS agents cannot simultaneously communicate with other agents, being only allowed one-on-one interactions among individual agents, i.e., the agents can only act as a client or as a server, which results in a lack of agent proactivity. In this way, if the agent detects a fault in its operation, it cannot communicate its fault to the network until another agent communicates with it. The absence of such functionality results in a poor microgrid critical resources management.

2) Agents individual behavior is easily to know, whereas that cannot be extended to the behavior of the whole system. To get the overall operation information about the microgrid dynamic network, clusters of agents working in the same microgrid application or with the same needs should be formed. The absence of such functionality might result in the lack of knowledge about the global status of the microgrid and, thus, in the sub-optimal resources allocation.

3) Agents have neither dynamic reorganization nor self-healing capabilities by themselves, which prevent to adapt to local-failures, microgrid blackouts, agents crashes or communication failures.

To overcome those limitations, a new generation of communication networks for microgrids is required. The new characteristics of those new networks are: i) Information exchange with neighboring DER management structures through virtual layers that allow dynamic reorganization, ii) Dynamic Reconfiguration and self-healing of DER management structures, iii) Better communication technologies for the proactive operation of devices and active consumers, and iv) New software layers at the TCP/IP protocol stack to meet the increasing microgrid service and complexity demands. These requirements are fulfilled by the new Peer-to-Peer (P2P) paradigm. Recent research suggests Peer-to-Peer (P2P) communication networks for microgrid environments which will give rise to the new dynamic distributed microgrids generation [97], [98], [99], [100], [101]. This argument is fully elaborated in the next section, as well as an implementation guideline.

\section{FUTURE TRENDS FOR DYNAMIC MICROGRIDS}

In spite of the progress discussed in the above sections, continued efforts are needed to address some issues associated with MAS decentralized communications on microgrids. A dynamic and complex system like a microgrid needs to be designed to adapt autonomously. P2P-based technology for distributed self-management could change the future of power grids, because the $\mathrm{P} 2 \mathrm{P}$ architecture has become a powerful control paradigm in a dynamic microgrid.

A P2P network is a communication architecture for decentralized systems. The agents, called peers, in contrast to MAS systems whose agents only can act as a server or a master, can act as both clients (masters) and servers simultaneously, which allows the agents to be proactive. Regarding P2P topology networks, the connectivity between nodes is essentially virtual, i.e. logical and structured topologies that are built on top of the physical networks [102] [Figure 7]. Peer nodes do not suffer from the inflexibility of MAS physical network topologies, since they are logical in nature. Their increased flexibility allows for extensibility, 
self-healing and dynamic reconfiguration. This implies that peers communicate with each other to establish dynamic self-organizing structures on top of the underlying physical networks. The fact that P2P overlays can be built dynamically allows them to support a huge variety of application level services [103]. In addition, these structures can be deployed over wired or wireless communications technologies. Routing can be achieved with direct point-topoint LAN communications without sacrificing the self-configuration, scalability and fault tolerance properties of a P2P overlay [104]. However, P2P overlay networks are ad-hoc in nature [105]. The nodes are connected by multi-hop wireless paths using technologies such as Zigbee/IEEE 802.15.4, Bluetooth/IEEE 802.15.1 and IEEE 802.11.

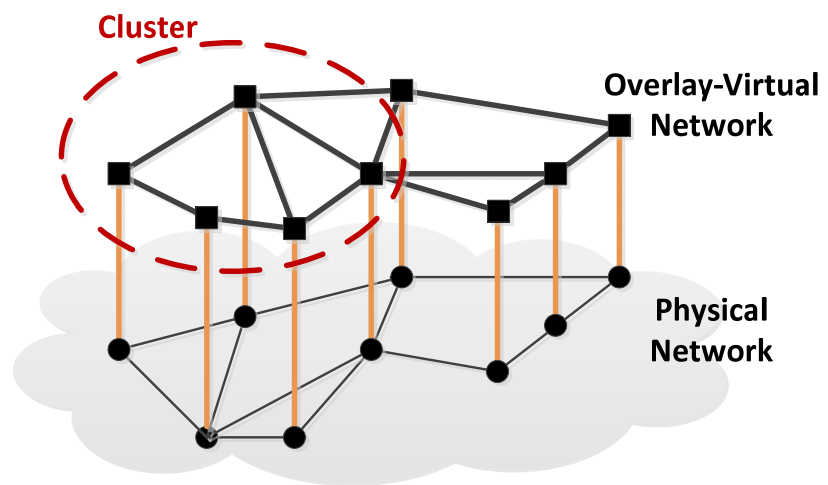

Fig.7. Overlay Network Architecture Scheme

Due to the virtual layer of the P2P architectures, peers disconnection from their underlying physical layer is allowed. This means that creation of a group of peers (clusters) for doing a particular task on a microgrid is possible [106]. Examples of clustering objectives include energy balancing, islanding and blackout prevention [37].

Therefore, virtual self-management allows agents to make local adaptive decisions on the basis of the information they receive from the agents to which they are linked [107], i.e., global goals are achieved by local management on the basis of local goals and knowledge. In this context, the holonic system approach has emerged [37], [108], [109]. This concept balances the importance of global and local objectives through a hierarchy of collaborative holons. The word holon is composed by "holos" meaning whole and the suffix "on" which implies particle or part, so holon=whole $\&$ part. Thus, the term comes from a recognition that any peer is simultaneously a whole entity comprised of sub-entities which interact to form different types of holarchy (based in P2P). Besides peers can find one another based on peers-IDs or peers attributes among the peers multitude. Thus, the responses to objects cached in the local overlay contain pointers to nodes that are close to the node issuing the query, thus reducing congestion on the network as well as network latencies [110].

Concerning mechanisms and protocols, the TCP/IP stack protocol is the most suitable standard for developing the peers. However, the overlays services need an additional software layer on the top of the TCP layer. Figure 8 presents a layered view about the different communication architectures for microgrids evolution. 


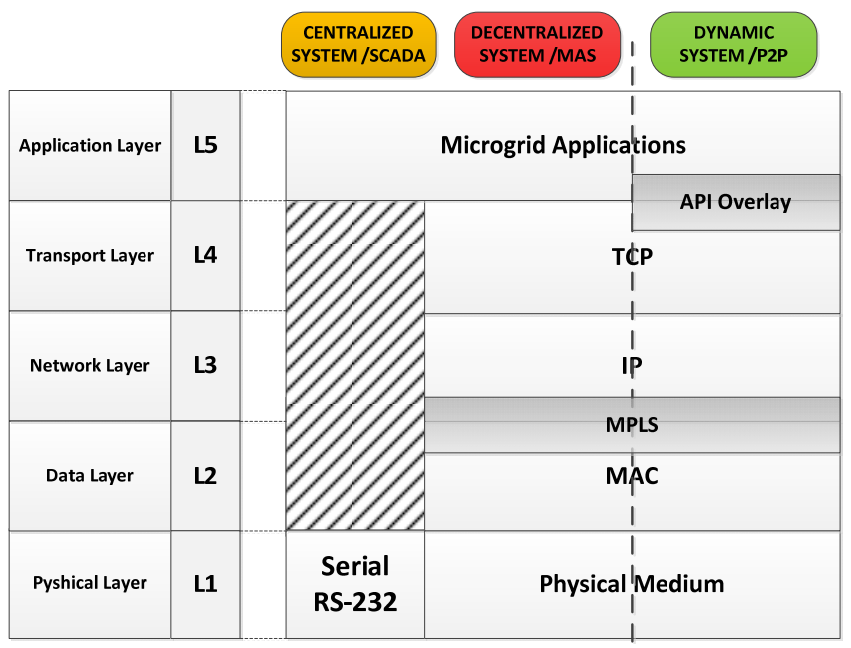

Fig.8. Protocol stack microgrid system evolution

The API Overlay layer is used to provide overlay-P2P services, being normally composed by two software layers: Overlay Routing and Messaging Layer and Overlay Management Layer (See Figure 9). Here, Software Defined Networking (SDN) is a need to virtualize networks.

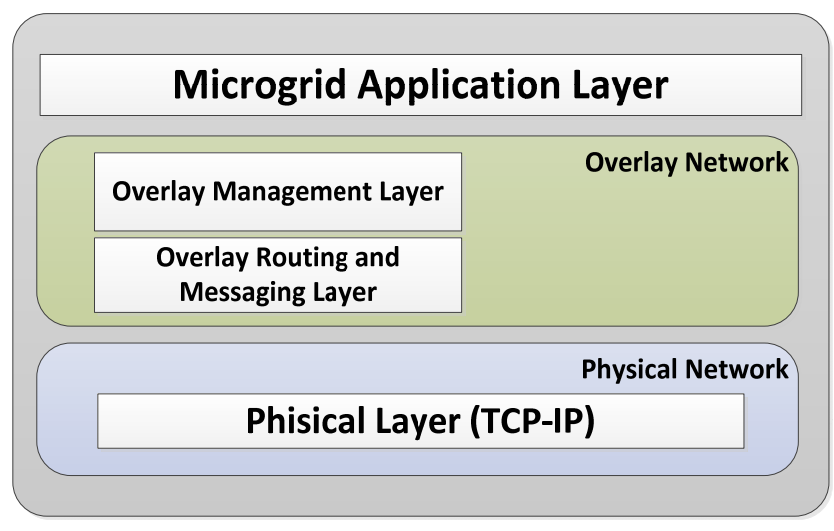

Fig.9. Stack Protocol of P2P Overlays

Overlay Routing and Messaging Layer provides networking P2P services to achieve the resource and network discovery, session establishment, routing, data transfer between nodes and entry/exit management of nodes (Plug and Play). The second application layer working on P2P service is responsible for the processing and data analysis, event management and status supervisory microgrid for stability maintenance.

As a result, it can conclude that this approach differs from conventional MAS in the dynamic and flexible cooperation, competition, supervision and part-whole. In addition, overlay structures combine the advantages of distributed control (such as scalability, adaptability and resiliency) and centralized control (reliability, optimally, practicability). Nevertheless, these P2P networks are still at the preliminary study stage for their implementation on the microgrid environment, being more research needed. Due to the growing complexity and unpredictability of the electrical systems, the study of microgrid dynamics becomes more complicated and new challenges arise which need to be addressed, such as: 
- Peer-to-peer networks are mainly developed for file and processor cycle sharing, whose network performance requirements are less critical [111]. Thus, adapt this network technology to the performance networking smart microgrid requirements is essential. In this regard, it is needed to extend IEC 61850 standard in order to include this decentralized control and interoperability [83], [84].

- The current microgrid applications are not able to manage the uncertainty variability of distributed energy resources, among other factors that can change over time, because the methods used are often based on linear models and deterministic forecasts that do not adequately manage the dynamic behavior of microgrids [112]. For this reason, advanced stochastic algorithms, predictive analytics and the use of nonlinear schemes should be applied into future microgrid applications to produce results with higher fidelity [113], [114], [115].

- The increasing number of renewable energy sources and microgeneration as well as the integration of a large amount of DER units in the microgrid requires advances in high performance computing and parallel processing. Due to get that, these methods require, on one side, greater quantities and greater speed in the data flow. On the other side, reduced processing data time and results in a more sensitive time scheme [116], [117]. Therefore, data compatibility and exchange are likely to emerge as major challenges for implementation of dynamic microgrid capabilities.

- Currently, the data repository implemented in microgrid system use different forms of data; they can be structured and unstructured data. The development of a universally compatible communications protocol to handle these diverse data forms is another challenge to carry out [118].

Overall, the improvements in microgrid control systems for the future advanced microgrid generation are focused on leveraging fundamental advances in communications, mathematics and software computation as well as enable better technologies needed to increase the ranges and applications of energy-efficient advanced microgrids [118]. Figure 10 shows a possible evolution path towards dynamic microgrids. The comparison criteria and results can be found in table 4.

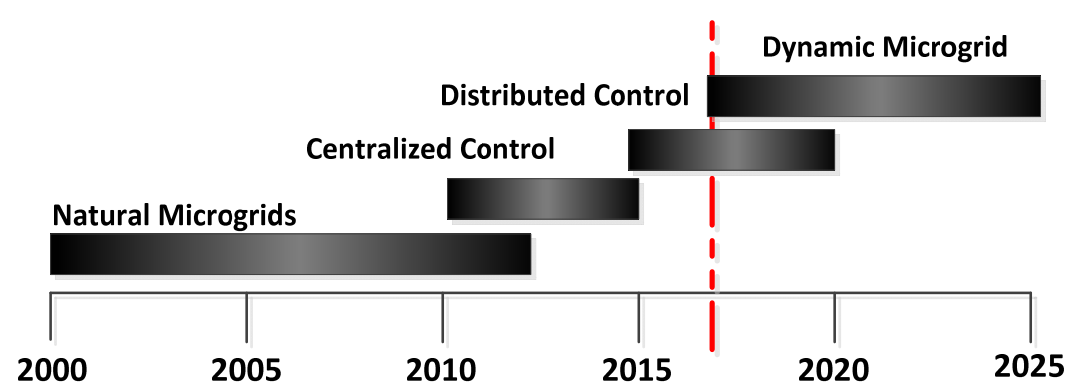

Fig.10. Roadmap to evolving to the dynamic microgrid. 


\begin{tabular}{|c|c|c|c|}
\hline & $\begin{array}{l}\text { CENTRALIZED } \\
\text { (SCADA) }\end{array}$ & $\begin{array}{l}\text { DECENTRALIZED } \\
\text { (MAS) }\end{array}$ & $\begin{array}{l}\text { DYNAMIC DISTRIBUTED } \\
\text { (P2P-Overlays) }\end{array}$ \\
\hline Access of information & $\begin{array}{l}\text { Status microgrid } \\
\text { information through the } \\
\text { whole units }\end{array}$ & $\begin{array}{l}\text { MAS provides each } \\
\text { independent control } \\
\text { with information about } \\
\text { its neighbor }\end{array}$ & $\begin{array}{l}\text { Control about neighbor or } \\
\text { cluster knowledge }\end{array}$ \\
\hline $\begin{array}{l}\text { Data communication } \\
\text { Structure }\end{array}$ & $\begin{array}{l}\text { Global \& synchronous } \\
\text { communication }\end{array}$ & $\begin{array}{l}\text { Local \& asynchronous } \\
\text { communication }\end{array}$ & $\begin{array}{l}\text { Local \& Global \& } \\
\text { asynchronous } \\
\text { communication }\end{array}$ \\
\hline Real-Time Functions & Difficult and expensive & Possible and inexpensive & Easy and inexpensive \\
\hline Plug \& Play Capacity & $\begin{array}{l}\text { MGCC must be } \\
\text { programmed }\end{array}$ & $\begin{array}{l}\text { Can be achieved without } \\
\text { any modification of the } \\
\text { controller }\end{array}$ & Inherent to peers \\
\hline Grid Model & Global grid model & Local grid model & $\begin{array}{l}\text { Local and Global grid } \\
\text { model }\end{array}$ \\
\hline Fault Tolerance Ability & $\begin{array}{l}\text { Poor fault tolerance } \\
\text { ability }\end{array}$ & $\begin{array}{l}1 \text { router failure } \rightarrow \text { tolerated } \\
\mathrm{n} \text { routers failure } \rightarrow \text { costly }\end{array}$ & $\begin{array}{l}\mathrm{n} \text { routers failure } \rightarrow \\
\text { tolerated } \\
\text { self-healing }\end{array}$ \\
\hline Flexibility \&Modularity & $\begin{array}{l}\text { Reconnection is required } \\
\text { for additional DERs }\end{array}$ & $\begin{array}{l}\text { MAS can install modular } \\
\text { and scalable systems }\end{array}$ & $\begin{array}{l}\text { Nodes can exit and enter } \\
\text { without changes in the } \\
\text { network }\end{array}$ \\
\hline Scale & Few nodes & $\begin{array}{l}\text { IPv4 } \rightarrow 2^{32} \text { nodes } \\
\text { IPv6 } \rightarrow 2^{128} \text { nodes } \\
\text { Hierarchical Domain }\end{array}$ & $\begin{array}{l}>2^{128} \text { nodes } \\
\text { Names Domain }\end{array}$ \\
\hline Destination Nodes & $\begin{array}{l}\text { Node identification not } \\
\text { allowed }\end{array}$ & $\begin{array}{l}\text { Unique IP identification } \rightarrow \\
\text { node }\end{array}$ & $\begin{array}{l}\text { GUID (Global Unique } \\
\text { Identifier) } \rightarrow \text { several host } \\
\text { nodes } \\
\text { (Routing at nearest) }\end{array}$ \\
\hline Interoperability & Not possible & Possible & Demanding \\
\hline Network Performance & $\begin{array}{l}\text { High Latencies and low } \\
\text { bandwidth. QoS not } \\
\text { allowed }\end{array}$ & $\begin{array}{l}\text { Greater latencies and } \\
\text { bandwidths. QoS is allowed }\end{array}$ & $\begin{array}{l}\text { Low latencies and high } \\
\text { bandwidth. Inherent QoS }\end{array}$ \\
\hline Network & Physical (EPA) & Physical (TCP/IP) & Virtual (o TCP/IP) \\
\hline Security & Poor & $\begin{array}{l}\text { Only where all nodes are } \\
\text { reliable }\end{array}$ & $\begin{array}{l}\text { Reachable, even in } \\
\text { unreliable environments }\end{array}$ \\
\hline Anonymity & Not possible & Not possible & To a limited extent \\
\hline
\end{tabular}

Table 4. Microgrid evolution system comparison

\section{CONCLUSIONS}

This paper has reviewed the evolution of microgrid communication systems, from those in initial microgrids to the emerging distributed systems. Recent research trends have been also discussed. This paper highlights that network communications in microgrids have more critical performance requirements than other IT systems due to the need for higher reliability, scalability, robustness, QoS and cybersecurity. The constraints of current microgrid communication systems, produced by the penetration growth of distributed energy resources, have been identified.

The research conducted up to date has produced important advances in communications achieving a decentralized and adaptable microgrid, having established a significant basis for the future deployment of new microgrids. It has been shown that intelligent, autonomous and communicative entities can lead to the successfully control of an energy system. The adoption of the TCP/IP stack protocol allows end to end communications and network interoperability. 
Improvements of the network topology to best fit dynamic and flexible environments have been described. However, research is still required towards the next generation of dynamic microgrids, where DERs are widely coupled into the energy systems and should be dynamically interoperated by means of ICT technologies.

The technical studies reported in the literature indicate that a new peer-to-peer communication system approach is required to support the transition from the current decentralized communication systems to the next microgrid generation. This argument is reinforced by the concept of holonic systems, which combine global and local objectives. A hierarchy of clusters (or holons) based on P2P is proposed in order to optimize the overall microgrid system performance.

Summing up, there are challenges and important open research issues that have been identified and discussed, whose main purpose is to enhance the performance of peer-to-peer communication networks for their operation on microgrids. Adaptive logic and stochastic software approaches can be used for reaching the goals.

\section{NOMENCLATURE}

\begin{tabular}{ll} 
CIM & Communication Information Model \\
DCCP & Data Congestion Control Protocol \\
DCHP & Dynamic Host Configuration \\
& Protocol \\
DER & Distributed Energy Resources \\
DG & Distributed Generation \\
Diffserv & Differentiation Services \\
DMS & Distribution Management System \\
DNO & Distribution Network Operator \\
DNP3 & Distributed Network Protocol 3 \\
DNS & Domain Name Service \\
DTLS & Datagram Transport Layer Security \\
EPA & Enhanced Performance Architecture \\
GOOSE & Generic Object Oriented Substations Events \\
GUID & Global Unique Identifier \\
HSPA & High Speed Packet Access \\
ICT & Information and Communication Technologies \\
IED & Intelligent Electronic Device \\
Intserv & Integrated Services \\
IP & Internet Protocol \\
IPsec & Internet Protocol Security \\
ISO/OSI & International Standards Organization/ Open Systems Interconnect \\
LC & Load Control \\
LTE & Long Term Evolution \\
MAC & Media Access Control \\
MACsec & Media Access Control Security \\
& \\
\hline
\end{tabular}




\begin{tabular}{|c|c|}
\hline MANET & Mobile Ad-hoc Network \\
\hline MAP & Mesh Access Point \\
\hline MAS & Multi Agent System \\
\hline MG & Microgrid \\
\hline MGCC & Microgrid Central Controller \\
\hline MMS & Manufacture Message Specification \\
\hline MO & Market Operator \\
\hline MPTCP & Multi Path Transport Control Protocol \\
\hline MS & Micro Source \\
\hline NAT & Network Access Translation \\
\hline NTP & Name Time Protocol \\
\hline OFDM & Orthogonal Frequency Division Multiplexing \\
\hline P2P & Peer-to-Peer \\
\hline PCC & Point of Common Coupling \\
\hline PLC & Power Line Carrier \\
\hline PPP & Point-to-Point Protocol \\
\hline QoS & Quality of Service \\
\hline RF-mesh & Radio Frequency mesh \\
\hline RLC & Radio Link Control \\
\hline RTMP & Real Time Measurement Parameters \\
\hline SCADA & Supervisory Control and Data Acquisition \\
\hline SCTP & Stream Control Transport Protocol \\
\hline SDH & Synchronous Digital Hierarchy \\
\hline SDN & Software Defined Networking \\
\hline SMG & Smart Microgrid \\
\hline SMV & Sampled Measured Values \\
\hline SNTP & Simple Network Time Protocol \\
\hline SONET & Synchronous Optical Network \\
\hline SS & Storage System \\
\hline SSL & Security Socket Layer \\
\hline SSTP & Scalable Secure Transport Protocol \\
\hline TCP & Transport Control Protocol \\
\hline TDM & Time Division Multiplexing \\
\hline TLS & Transport Layer Security \\
\hline ToS & Type of Service \\
\hline UDP & User Datagram Protocol \\
\hline WDM & Wave Division Multiplexing \\
\hline WLAN & Wireless Local Area Network \\
\hline WMAN & Wireless Metropolitan Area Network \\
\hline WMN & Wireless Mesh Network \\
\hline WPAN & Wireless Personal Area Network \\
\hline WWAN & Wireless Metropolitan Area Network \\
\hline
\end{tabular}




\section{ACKNOWLEDGEMENTS}

This work is supported by the Spanish Ministry of Economy and Competitiveness (MINECO) and the European Regional Development Fund (ERDF) under Grant ENE2015-64087-C2-2.

This work is supported by the Spanish Ministry of Economy and Competitiveness (MINECO) under grant BES-2013-064539.

\section{References}

[1] G. Gutiérrez-Alcaraz, E. Galván, N. González-Cabrera and M. Javadib, "Renewable energy resources short-term scheduling and dynamic network reconfiguration for sustainable energy consumption," Renewable and Sustainable Energy Reviews, vol. 52, p. 256-264, 2015.

[2] Y. Yoldaş, A. Önen, S. M. Muyeen, A. V. Vasilakos and İ. Alan, " Enhancing smart grid with microgrids: Challenges and opportunities," Renewable and Sustainable Energy Reviews, , vol. 72, pp. 205-214, 2017.

[3] H. Reduan and J. Khyan, "A Comprehensive Review of the Application Characteristics and Traffic Requirements of a Smart Grid Communications Network," Computer Networks, vol. 57, no. 3, pp. 825-845, 2013.

[4] J. O. Dada, "Towards understanding the benefits and challenges of Smart/Micro-Grid for electricity supply system in Nigeria," Renewable and Sustainable Energy Reviews, vol. 38, p. 1003-1014, 2014.

[5] O. Palizban, K. Kauhaniemi and J. M. Guerrero, "Microgrids in Active Network Management - Part II: System Operation, Power Quality and Protection," Renewable and Sustainable Energy Reviews, vol. 36, pp. 440-441, 2014.

[6] D. Olivares, A. Mehrizi-Sani, A. Etemadi, C. Canizares, R. Iravani, M. Kazerani, A. Hajimiragha, O. Gomis-Bellmunt, M. Saeedifard, R. Palma-Behnke, G. Jimenez-Estevez and N. Hatziargyriou, "Trends in Microgrid Control," IEEE Transactions on Smart Grid, vol. 5, no. 4, pp. 1905-1919, 2014.

[7] I. Patrao, E. Figueres, G. Garcerá and R. González-Medina, "Microgrid architectures for low voltage distributed generation," Renewable and Sustainable Energy Reviews, vol. 43, pp. 415-424, 2015.

[8] K. S. Rajesh, S. S. Dash, R. Rajagopal and R. Sridhar, " A review on control of ac microgrid," Renewable and Sustainable Energy Reviews, vol. 71, pp. 814-819, 2017. 
[9] E. Planasa, A. Gil-de-Murob, J. Andreua, I. Kortabarriaa and I. Martínez de Alegríaa, "General aspects, hierarchical controls and droop methods in microgrids: A review," Renewable and Sustainable Energy Reviews., vol. 17, p. 147-159, 2013.

[10] B. Zhou, W. Li, K. Wing Chan, Y. Cao, Y. Kuang, X. i Liu and X. Wang, "Smart home energy management systems: Concept, configurations, and scheduling strategies," Renewable and Sustainable Energy Reviews., vol. 61, pp. 30-40, 2016.

[11] A. Bani-Ahmed and L. Weber, "Microgrid communication: State of the art and future trends," 3rd The International Conference on Renewable Energy Research and Applications, 2014.

[12] IEC, "IEC 61850-7-420. Communication networks and system in power utility automation - Part 7-420: Basic communication structure - distributed energy resources logical nodes," 2009.

[13] K. M. Muttaqi, J. Aghaei, V. Ganapathy and A. E. Nezhad, "Technical challenges for electric power industries with implementation of distribution system automation in smart grids," Renewable and Sustainable Energy Reviews, vol. 46, pp. 129-142, 2015.

[14] A. Bonfiglio, L. Barillari, F. Delfino, F. Pampararo, R. Procopio, M. Rossi, M. Invernizzi, G. Denegri and S. Bracco, "The smart microgrid pilot project of the university of genoa: Power and communication architectures," AEIT Annual Conference, Mondello, pp. 1-6, 2013.

[15] W. Dong, Y. Lu, M. Jafari, P. Skare and K. Rohde, "An integrated security system of protecting smart grid against cyber-attacks," Innovative Smart Grid Technologies (ISGT),2010, Gaithersburg, pp. 1-7, 2010.

[16] X. Fang, M. Satyajayant, X. Guoliang and Y. Dejun, "Smart Grid - The New and Improved Power Grid: A Survey," Communications Surveys \& Tutorials, IEEE, vol. 14, no. 4, pp. 944,980, 2012.

[17] E. Hossain, E. Kabalci, R. Bayindir and R. Perez, "A Comprehensive Study on Microgrid Technology," International Journal of Renewable Energy Research, vol. 4, no. 4, 2014.

[18] C. M. Colson and M. H. Nehir, "A review of challenges to real-time power management of microgrids," 2009 IEEE Power \& Energy Society General Meeting, Calagary, pp. 1-8, 2009.

[19] E. Hossain, E. Kabalci, R. Bayindir and R. Perez, "Microgrid testbeds around the world: State of art," Energy conversion and management, vol. 86, pp. 132-153, 2014.

[20] E. Ancillotti, R. Bruno and M. Conti, "The role of communication systems in smart grids: Architectures, technical solutions and research challenges," Computer Communications, 
vol. 36, no. 17-18, p. 1665-1697, 2013.

[21] Y. Seyedi, H. Karimi and J. M. Guerrero, "Centralized Disturbance Detection in Smart Microgrids With Noisy and Intermittent Synchrophasor Data," IEEE Transactions on Smart Grid., vol. 1, no. 1, 2016.

[22] S. Safdar, B. Hamdaoui, E. Cotilla-Sanchez and M. Guizani, "A survey on communication infrastructure for micro-grids," 9th International Wireless Communications and Mobile Computing Conference (IWCMC), pp. 545-550., 2013.

[23] P. Kansal and A. Bose, "Bandwidth and latency requirements for smart transmission grid applications," IEEE Transactions on Smart Grid, vol. 3, no. 3, pp. 1344-1352, 2012.

[24] IEC, "IEC 61850-5 communication networks and systems in substations - Part 5: communication requirements for functions and device models".

[25] "IEEE 1646 standard communication delivery time performance requirements for electric power substation automation," 2004.

[26] "IEC 61850: Communication Networks and Systems in Substations; International Electrotechnical Commission:Geneva, Switzerland, 2002".

[27] W. Wang, Y. Xu and M. Khanna, "A survey on the communication architectures in smart grid," Computer Networks, vol. 55, no. 15, pp. 3604-3629, 2011.

[28] M. Short, F. Abugchem and M. Dawood, " Tunneling Horizontal IEC 61850 Traffic through Audio Video Bridging Streams for Flexible Microgrid Control and Protection," Energies, vol. 9, no. 3, p. 204, 2016.

[29] J. Hare, X. Shi, S. Gupta and A. Bazzi, "Fault diagnostics in smart micro-grids: A survey," Renewable and Sustainable Energy Reviews, vol. 60, pp. 1114-1124, 2016.

[30] Q. Yang, J. A. Barria and T. C. Green, "Communication infrastructures for distributed control of power distribution networks," EEE Transactions on Industrial Informatics, vol. 7, no. 2, pp. 316-327, 2011.

[31] Z. Lu, C. Sun, J. Cheng, Y. Li, Y. Li and X. Wen, " SDN-Enabled Communication Network Framework for Energy Internet.," Journal of Computer Networks and Communications, 2017.

[32] L. Ren, Y. Qin, B. Wang, P. Zhang, P. B. Luh and R. Jin, " Enabling resilient microgrid through programmable network," IEEE Transactions on Smart Grid, 2016.

[33] J. Sánchez, I. G. Yahia and N. Crespi, "POSTER: Self-Healing Mechanisms for SoftwareDefined Networks," 2015. 
[34] A. Mohan, G. Brainard, H. Khurana and S. Fischer, "A cyber security architecture for microgrid deployments," IFIP International Federation for Information Processing 2015 M. Rice, S. Shenoi (Eds.): Critical Infrastructure Protection IX.

[35] N. Moreira, E. Molina, J. Lázaro, E. Jacob and A. Astarlo, "Cyber-security in substation automation systems," Renew Sustain Energy Rev., vol. 54, p. 1552-1562., 2016.

[36] A. Kantamneni, L. E. Brown, G. Parker and W. W. Weaver, "Survey of multi-agent systems for microgrid control," Engineering Applications of Artificial Intelligence, vol. 45, p. 192203., 2015.

[37] S. Howell, Y. Rezgui, J. L. Hippolyte, B. Jayan and H. Li, "Towards the next generation of smart grids: Semantic and holonic multi-agent management of distributed energy resources," Renewable and Sustainable Energy Reviews, vol. 77, pp. 193-214, 2017.

[38] S. Parhizi, H. Lotfi, A. Khodaei and S. Bahramirad, "State of the Art in Research on Microgrids: A Review," IEEE Access, vol. 3, pp. 890-925, 2015.

[39] Y. S. Eddy, H. B. Gooi and S. X. Chen, "Multi-Agent System for Distributed Management of Microgrids," IEEE Transactions on Power Systems, vol. 30, no. 1, pp. 24-34, 2015.

[40] R. Bayindir, E. Hossain, E. Kabalci and R. Perez, "A comprehensive study on microgrid technology," International Journal of Renewable Energy Research, vol. 4, no. 4, pp. 10941107, 2014.

[41] Y. Kabalci, " A survey on smart metering and smart grid communication," Renewable and Sustainable Energy Reviews, vol. 57, pp. 302-318, 2016.

[42] K. Christensen and B. Nordman, "Back to the future: A need for multi-drop Ethernet for cost-effective power distribution.," In Local Computer Networks (LCN), 2014 IEEE 39th Conference on IEEE., pp. 378-381, 2014.

[43] K. Venkatraman, B. D. Reddy, M. P. Selvan, S. Moorthi, N. Kumaresan and N. A. Gounden, " Online condition monitoring and power management system for standalone micro-grid using FPGAs," IET Generation, Transmission \& Distribution,, vol. 10, no. 15, pp. 38753884, 2016.

[44] A. Mahmood, N. Javaid and S. Razzaq, " A review of wireless communications for smart grid," Renewable and Sustainable Energy Reviews, vol. 41, pp. 248-260, 2015.

[45] A. Llaria, G. Terrasson, O. Curea and J. Jiménez, "Application of Wireless Sensor and Actuator Networks to Achieve Intelligent Microgrids: A Promising Approach towards a Global Smart Grid Deployment," Appl. Sci, vol. 6, no. 3, p. 61, 2016.

[46] R. Carvalho, R. Demo and M. E. Pellenz, "Overlay Cognitive Radio in Wireless Mesh 
Networks," Wireless Personal Communications, vol. 55, no. 2, pp. 237-251, 2010.

[47] F. Liu and Y. Bai, "An overview of topology control mechanisms in multi-radio multichannel wireless mesh networks," EURASIP Journal on Wireless Communications and Networking, p. 324, 2012.

[48] R. Teng, H. B. Li, R. Miura, T. Yamazaki and P. Davis, "Matching of energy provisions in multihop wireless infra-structures," Energies, vol. 9, no. 1, p. 45, 2016.

[49] M. Li, H. Nishiyama, N. Kato, Y. Owada and K. Hamaguchi, " On the energy-efficient of throughput-based scheme using renewable energy for wireless mesh networks in disaster area," IEEE Transactions on Emerging Topics in Computing, vol. 3, no. 3, pp. 420431., 2015.

[50] H. Elkhorchani and K. Grayaa, "Smart micro Grid power with wireless communication architecture," In Electrical Sciences and Technologies in Maghreb (CISTEM), 2014 International Conference on IEEE., pp. 1-10, 2014.

[51] U. Ashraf, "Energy-Aware Gateway Placement in Green Wireless Mesh Networks," IEEE Communications Letters., vol. 21, no. 1, 2017.

[52] N. S. Nandiraju, D. S. . Nandiraju and D. P. Agrawal, "Multipath Routing in Wireless Mesh Networks," IEEE International Conference on Mobile Ad Hoc and Sensor Systems, pp. 741746, 2006.

[53] H. Jeong, H. Yoo, D. Kim and J. Park, "Multipath Routing Based on Path Bandwidth in Multi-channel Wireless Mesh Networks," Recent Trends in Wireless and Mobile Networks. Volume 84 of the series Communications in Computer and Information Science, pp. 1-12, 2010.

[54] K. Pantelaki, S. Panagiotakis and A. Vlissidis, "Survey of the IEEE 802.15.4 Standard's Developments for Wireless Sensor Networking," American Journal of Mobile Systems Applications and Services, vol. 2, no. 1, pp. 13-31, 2016.

[55] M. Lee, R. Zhang, C. Zhu, T. R. Park, C.-. S. Shin, Y.-A. Jeon, S.-H. Lee, S.-S. Choi, Y. Liu and S.-W. Park, "Meshing Wireless Personal Area Networks: Introducing IEEE 802.15.5," IEEE Communications Magazine, vol. 48, no. 1, pp. 54-61, 2010.

[56] G. R. Hiertz, Y. Zang, S. Max, T. Junge, E. Weiss, B. Wolz, D. Denteneer, L. Berlemann and S. Mangold, "IEEE 802.11s: WLAN mesh standardization and high performance extensions," IEEE Network, vol. 22, no. 3, pp. 12-19, 2008.

[57] H. Wei, J. Rykowski and S. Dixit, "WiFi, WiMAX and LTE Multi-hop Mesh Networks: Basic Communication Protocols and Application Areas," 1st. Wiley Publishing, 2013. 
[58] N. Suljanovic, D. Borovina, M. Zajc, J. Smajic and A. Mujcic, " Requirements for communication infrastructure in smart grids.," In Energy Conference (ENERGYCON), 2014 IEEE International , pp. 1492-1499, 2014.

[59] A. Muhammad, Z. M. A. Muhammad and U. Amjad, "TCP/IP based intelligent load management system in micro-grids network using MATLAB/Simulink," Energy and Power Engineering, 2012.

[60] T. Khalifa, A. Abdrabou, K. Naik, M. Alsabaan, A. Nayak and N. Goel, " Split-and aggregated-transmission control protocol (SA-TCP) for smart power grid," IEEE Transactions on Smart Grid, vol. 1, no. 5, pp. 381-391, 2014.

[61] J. Liu, H. Guo, H. Nishiyama, H. Ujikawa, K. Suzuki and N. Kato, "New Perspectives on Future Smart FiWi Networks: Scalability, Reliability, and Energy Efficiency," IEEE Communications Surveys \& Tutorials, vol. 2, no. 18, pp. 1045-1072, 2016.

[62] D. P. Van, B. P. Rimal and M. Maier, " Fiber optic vs. wireless sensors in energy-efficient integrated FiWi smart grid networks: An energy-delay and TCO comparison.," In Computer Communications, IEEE INFOCOM 2016-The 35th Annual IEEE International Conference, pp. 1-9, 2016.

[63] R. Charni and M. Maier, "Total cost of ownership and risk analysis of collaborative implementation models for integrated fiber-wireless smart grid communications infrastructures," IEEE Transactions on Smart Grid, vol. 5, no. 5, pp. 2264-2272, 2014.

[64] M. Mohsin, W. Wong and Y. Bhutt, "Support for real-time traffic in the Internet, and QoS issues," A survey of QoS protocols for the Internet., 2002.

[65] W. Zhao, D. Olshefski and H. Schulzrinne, "Internet quality of service: An overview.," New York, Technical Report CUCS-003-00., 2000.

[66] F. Alharbi and Z. Fei, " Improving the quality of service for critical flows in smart grid using software-defined networking.," IEEE International Conference Smart Grid Communications (SmartGridComm), , pp. 237-242, 2016.

[67] P. Trimintzios, I. Andrikopoulos, G. Pavlou and e. al, "A management and control architecture for providing IP differentiated services in MPLS-based networks," IEEE Communications Magazine, vol. 5, no. 39, pp. 80-88, 2001.

[68] N. Saputroa, K. Akkayaa and S. Uludagb, "A survey of routing protocols for smart grid communications," Computer Networks., vol. 56, no. 11, pp. 2742-2771, 2012.

[69] L. B. Saad, C. Chauvenet and B. Tourancheau, " IPv6 (Internet Protocol version 6) heterogeneous networking infrastructure for energy efficient building," Energy, vol. 1, no. 44, pp. 447-157, 2012. 
[70] S. Steffann, I. Van Beijnum and R. Van Rein, "A Comparison of IPv6-over-IPv4 Tunnel Mechanisms," IETF RFC 7059, 2013.

[71] C. K. Veitch, J. M. Henrt, B. T. Richardson and D. H. Hart, "Microgrid Cyber Security Reference Architecture," Sandia National Laboratories, operated for the United States Department of Energy, 2013.

[72] K. Shuaib, I. Khalil and M. Abdel-Hafez, "Communications in Smart Grid: A Review with Performance, Reliability and Security Consideration," Journal of Networks, vol. 6, no. 8, pp. 1229-1240, 2013.

[73] T. Stegel, J. Sterle, U. Sedlar, J. Bešter and A. Kos, "SCTP multihoming provisioning in converged IP-based multimedia environment," Computer Communications .Special Issue on Multimedia Networking and Security in Convergent Networking, vol. 33, no. 14, pp. 1725-1735, 2010.

[74] Y. J. Kim, V. Kolesnikov and H. T. M. Kim, "SSTP: A scalable and secure transport protocol for smart grid data collection," IEEE International Conference on Smart Grid Communications. Institute of Electrical and Electronics Engineers, New York,, pp. 161166, 2011.

[75] A. Ford, C. Raiciu, M. Handley and O. Bonaventure, "TCP Extensions for Multipath Operation with Multiple Addresses.," RFC 6824. Internet Engineering Task Force, 2013.

[76] C. Paasch, R. Khalili and O. Bonaventure, "On the Benefits of Applying Experimental Design to Improve Multipath TCP," Proceedings of the ninth ACM conference on Emerging networking experiments and technologies, pp. 393-398, 2013.

[77] "IEEE Guide for Smart Grid Interoperability of Energy Technology and Information Technology Operation with the Electric Power System (EPS), End-Use Applications, and Loads," Standards, IEEE. IEEE Std 2030-2011, pp. 1-126., 2011.

[78] IEC, "IEC 61850-7-420 communications standard for distributed energy resources (DER)".

[79] IEC, International Standard IEC 61968. <http://www.iec.ch>..

[80] «IEEE, IEEE Application guide for IEEE Std 1547, IEEE standard for interconnecting distributed resources with electric power systems.<http://www.ieee.org>.».

[81] «IEEE, IEEE 1547.3-2007, IEEE GUIDE for Monitoring, Information Exchange, and Control of Distributed Resources Interconnected with Electric Power Systems,» 2007.

[82] «IEEE Standard Communication Delivery Time Performance Requirements for Electric Power Substation Automation,» IEEE Std 1646-2004, pp. 1-24, 2005. 
[83] B. Duan, C. Tan y Y. Liu, «Towards Harmonization IEC61850 and Intelligent Agents: Characteristic Analysis of Service Tracking",» Energy and Power Engineering, vol. 5, pp. 1308-1311, 2013.

[84] A. Saleem, N. Honeth and L. Nordström, "A case study of multi-agent interoperability in IEC 61850 environments," 2010 IEEE PES Innovative Smart Grid Technologies Conference Europe (ISGT Europe), Gothenburg, pp. 1-8, 2010.

[85] S. Alizadeh y C. Ozansoy, "The role of communications and standardization in wind power applications - A review, ") Renew Sustain Energy Rev., vol. 54, p. 944-958., 2016.

[86] A. Mohan and H. Khurana, "Implementing Cyber Security Requirements and Mechanisms in Microgrids," Springer International Publishing In International Conference on Critical Infrastructure Protection, pp. 229-244, 2015.

[87] J. Seppälä, H. Koivisto, P. Jafary and S. Repo, " Security and reliability analysis of a use case in smart grid substation automation systems," IEEE In Industrial Technology (ICIT). IEEE International Conference, pp. 615-620, 2017.

[88] H. He and J. Yan, "Cyber-physical attacks and defences in the smart grid: a survey," IET Cyber-Physical Systems: Theory \& Applications, vol. 1, no. 1, pp. 13-27, 2016.

[89] R. Garduno-Ramirez and M. Borunda, "An intelligent multi-agent based improved approach for conventional and renewable power generation operation and control," Journal of Renewable and Sustainable Energy, vol. 9, no. 1, 2017.

[90] A. Kulasekara, K. Hemapala and R. Gopura, "Dual layered architecture for multi agent based islanding and load management for microgrids," Journal of Power and Energy Engineering, ., vol. 3, no. 5, p. 29, 2015.

[91] H. K. Nunna, A. M. Saklani, A. Sesetti, S. Battula, S. Doolla and D. Srinivasan, "Multi-agent based Demand Response management system for combined operation of smart microgrids," Sustainable Energy, Grids and Networks, vol. 6, pp. 25-34, 2016.

[92] A. Lopes and Botelho.L, "Improving Multi-Agent Based Resource Coordination in Peer-toPeer Networks," Journal of Networks, vol. 3, no. 2, 2008.

[93] E. Del Val, M. Rebollo and V. Botti, " Enhancing decentralized service discovery in open service-oriented multi-agent systems.," Autonomous agents and multi-agent systems, pp. 1-30, 2014.

[94] E. del Val, M. Rebollo and V. Botti, "Self-organization in service discovery in presence of noncooperative agents," Neurocomputing, vol. 176, pp. 81-90, 2016.

[95] D. Di Mauro, J. C. Augusto, A. Origlia and F. Cutugno, "A framework for distributed 
interaction in intelligent environments.," In European Conference on Ambient Intelligence. Springer, Cham., pp. 136-151, 2017.

[96] O. Babaoglu, H. Meling and A. Montresor, "Anthill: A framework for the development of agent-based peer-to-peer systems," IEEE 22nd International Conference on System Proceedings, pp. 15-22, 2002.

[97] C. Giotitsas, A. Pazaitis and V. Kostakis, "A peer-to-peer approach to energy production," Technology in Society, vol. 42, pp. 28-38, 2015.

[98] T. Liu, X. Tan, B. Sun, Y. Wu, X. Guan and D. H. Tsang, " Energy management of cooperative microgrids with p2p energy sharing in distribution networks.," In Smart Grid Communications (SmartGridComm), 2015 IEEE International Conference on IEEE, pp. 410415, 2015.

[99] H. Almasalma, J. Engels and G. Deconinck, "Peer-to-Peer Control of Microgrids.," Proc. IEEE YRS 2016. IEEE Benelux PELS/PES/IAS Young Researchers Symposium. Eindhoven, Netherlands, 2016.

[100] A. Werth, A. Andre, D. Kawamoto, T. Morita, S. Tajima, D. Yanagidaira and K. Tanaka, "Peer-to-peer Control System for DC Microgrids," IEEE Transactions on Smart Grid., 2016.

[101] T. AlSkaif, M. G. Zapata, B. Bellalta and A. Nilsson, "A distributed power sharing framework among households in microgrids: a repeated game approach.," Computing, vol. 1, no. 99, pp. 23-37, 2017.

[102] A. Gupta, "Peer-to-Peer networks and computation: Current trends and future perspectives," Computing and Informatics, vol. 30, p. 559-594, 2011.

[103] A. Malatras, "State-of-the-art survey on P2P overlay networks in pervasive computing environments," Journal of Network and Computer Applications, vol. 55, pp. 1-23, 2015.

[104] D. I. Wolinsky, Y. Liu, P. S. Juste, G. Venkatasubramanian and R. Figueiredo, " On the design of scalable, self-configuring virtual networks.," In Proceedings of the Conference on High Performance Computing Networking, Storage and Analysis, p. 12, 2009.

[105] E. K. Lua, J. Crowcroft, M. Pias, R. Sharma and S. Lim, " A survey and comparison of peerto-peer overlay network schemes.," IEEE Communications Surveys \& Tutorials, vol. 7, no. 2, pp. 72-93, 2005.

[106] S. G. Fantar and H. Youssef, " Exploiting locality using geographic coordinates and semantic proximity in Chord," IEEE Symposium on Computers and Communications (ISCC), pp. 1091-1096, 2010.

[107] F. Brazier, E. Ogston and M. Warnier, " The future of energy markets and the challenge 
of decentralized self-management.," In Agents and Peer-to-Peer Computing. Springer Berlin Heidelberg., pp. 95-103, 2012.

[108] S. Frey, A. Diaconescu, D. Menga and I. Demeure, " A generic holonic control architecture for heterogeneous multiscale and multiobjective smart microgrids," ACM Transactions on Autonomous and Adaptive Systems (TAAS), vol. 2, no. 10, p. 9, 2015.

[109] T. Strasser, F. Andrén, J. Kathan, C. Cecati, C. Buccella, P. Siano and V. Mařík, "A review of architectures and concepts for intelligence in future electric energy systems.," IEEE Transactions on Industrial Electronics,, vol. 62, no. 4, pp. 2424-2438., 2015.

[110] A. Mawji and H. Hassanein, "Efficient content distribution for peer-to-peer overlays on mobile ad hoc networks," Special issue on Mobile Ad-Hoc Wireless Networks, vol. 2, no. 3, pp. 265-279, 2011.

[111] H. D. Bandara and A. P. Jayasumana, "Collaborative applications over peer-to-peer systems-challenges and solutions," Peer-to-Peer Networking and Applications, vol. 6, no. 3, pp. 257-276, 2013.

[112] A. Hussain, V. H. Bui and H. M. Kim, "Robust Optimization-Based Scheduling of MultiMicrogrids Considering Uncertainties.," Energies, vol. 9, no. 4, p. 278, 2016.

[113] A. Mesbah, "Stochastic model predictive control: An overview and perspectives for future research," IEEE Control Systems Magazine,, 2016.

[114] S. Cominesi, M. Farina, L. Giulioni, B. Picasso and R. Scattolini, "Two-layer predictive control of a micro-grid including stochastic energy," Proceedings of the American Control Conference, p. 918-923, 2015.

[115] C. A. Hans, P. Sopasakis, A. Bemporad, J. Raisch and C. ReinckeCollon, "Scenario-based model predictive operation control of islanded," Proceedings of the 54th IEEE Conference on Decision and Control, Osaka, Japan, 2015.

[116] W. Chen, K. Zhou, S. Yang and C. Wu, "Data quality of electricity consumption data in a smart grid environment," Renewable and Sustainable Energy Reviews, vol. 75, pp. 98105, 2017.

[117] B. C. Neagu, G. Grigoraş and F. Scarlatache, " Outliers discovery from Smart Meters data using a statistical based data mining approach.," In Advanced Topics in Electrical Engineering (ATEE), 2017 10th International Symposium, pp. 555-558, 2017.

[118] W. I. Bower, D. T. Ton, R. Guttromson, S. F. Glover, J. E. Stamp, D. Bhatnagar and J. Reilly, "The advanced microgrid. Integration and interoperability," Sandia National Laboratories (SNL-NM), Albuquerque, NM (United States, no. SAND2014--1535, 2014. 
